\title{
Atmospheric Deposition Program of the U.S. Geological Survey
}

\section{INTRODUCTION}

Nearly 200 million tons of criteria air pollutants (sulfur dioxide, nitrogen dioxide, carbon monoxide, lead, volatile organic compounds, and particulate matter) were emitted in the United States in 1997 (U.S. Environmental Protection Agency, 1998). These and other pollutants can be returned to the earth through the processes of wet and dry atmospheric deposition. Wet deposition removes gases and particles in the atmosphere and deposits them to the Earth's surface by means of rain, sleet, snow, and fog. Dry deposition is the process through which particles and gases are deposited in the absence of precipitation. In 1980, the federally supported interagency National Acid Precipitation Assessment Program (NAPAP) was established to provide broadened support for research into the causes and effects of acid deposition. Under NAPAP, the U.S. Geological Survey (USGS) was designated as the lead Federal agency for the monitoring of wet atmospheric deposition in the United States. Currently, the USGS atmospheric-deposition program provides:

- Continuous measurement and assessment of the chemical constituents in precipitation throughout the United States through participation and leadership in the National Atmospheric Deposition Program (NADP).

- Scientific research and assessment to evaluate the effects of atmospheric deposition on aquatic and terrestrial ecosystems.

This long-term, nationally consistent monitoring program, coupled with ecosystem research, provides critical information

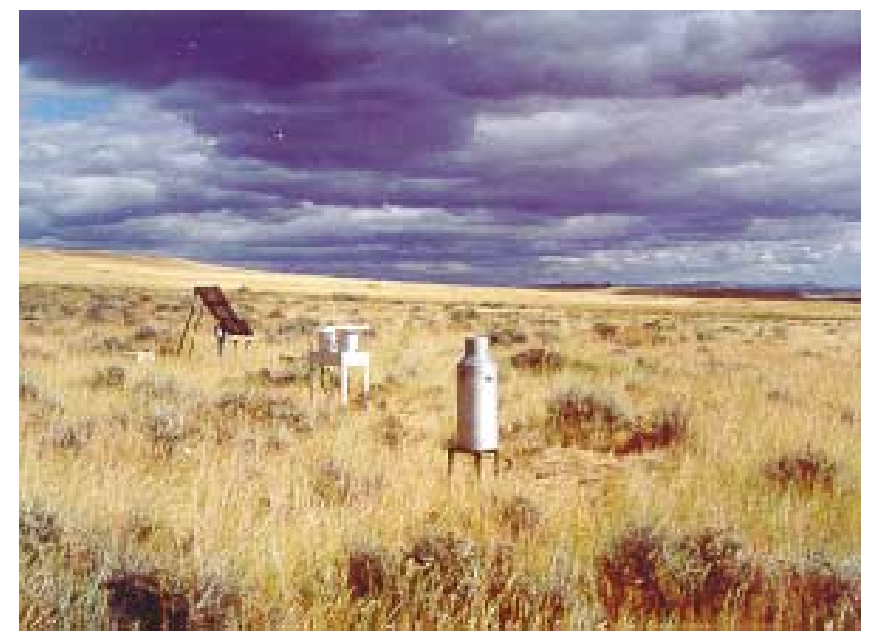

Figure 1. An atmospheric-deposition-monitoring site at Little Bighorn Battlefield National Monument in Montana. toward a national scorecard to evaluate the effectiveness of ongoing and future regulations intended to reduce atmospheric emissions and subsequent impacts to the Nation's land and water resources. Monitoring data from sites, such as the one shown in figure 1, and on-line program reports are available through the Internet at http://bqs.usgs.gov/acidrain.

\section{PROVIDING FEDERAL LEADERSHIP IN THE NATIONAL ATMOSPHERIC DEPOSITION PROGRAM}

The NADP consists of over 100 organizations, including 8 Federal agencies, State governments, universities, tribal nations and private companies. These organizations share resources to provide the Nation with a long-term, high-quality data base of atmospheric deposition generated from networks of precipitationchemistry monitoring sites. The largest of these networks is the 220-site National Trends Network (NTN) (fig. 2). Every NTN site uses identical equipment and operating protocols and operates continuously to monitor precipitation chemistry. Samples from NTN sites are analyzed for sulfate, nitrate, ammonium, phosphate, $\mathrm{pH}$, chloride, calcium, magnesium, sodium, potassium, and specific conductance.

The USGS is the lead Federal agency in the NADP and supports 72 of the NADP's NTN stations. Since the inception of the network, the USGS has also provided an extensive external quality-assurance program for the entire NTN (Gordon, 1999).

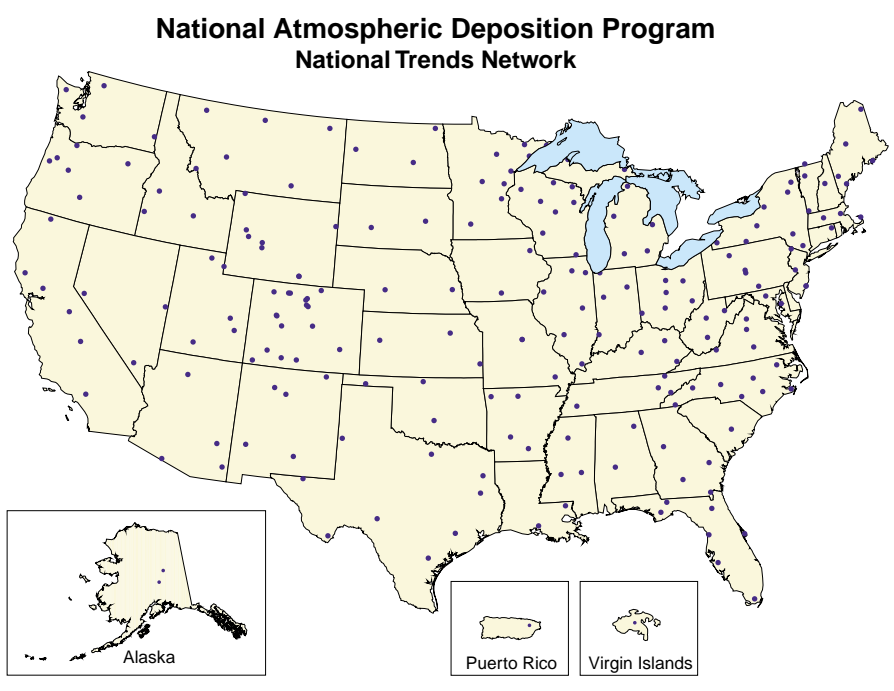

Figure 2. Location of sites in the National Atmospheric Deposition Program, National Trends Network. 
The NTN has one of the longest multisite records of precipitation chemistry in the world.

\section{EVALUATING THE EFFECTIVENESS OF THE CLEAN AIR ACT AMENDMENTS}

Through the end of 1994, the value of electric utility company investments in environmental protection measures amounted to more than $\$ 60$ billion. Over the last two decades, utility companies have spent an additional $\$ 40$ billion on operating and maintaining environmental control systems (Electric Power Research Institute, 1996). Estimates for the cost of implementing the sulfur dioxide emissions control program mandated by the 1990 Clean Air Act Amendments (CAAA) are expected to be about $\$ 600$ million per year by 2015 . These costs may be passed on to the public in the form of higher costs for energy, transportation, and other goods and services. The first phase of emission reductions under the 1990 CAAA, Title IV, began in January 1995, at 445 coal-burning electric utility plants, primarily located in the Midwest and Northeastern United States. Phase II began in 2000 and affects about five times the number of electric utility plants as Phase I. The USGS atmospheric-deposition program regularly provides data and assessments of trends in atmospheric deposition (for example; Lynch, 1996) to the scientific and policy community to determine if these regulatory actions are providing the desired outcome, namely an improvement in the quality of the Nation's precipitation chemistry with subsequent reduction in adverse environmental impacts to land and water resources. In the latest interagency report to Congress, the USGS reported that Phase I of the CAAA-90, Title IV, has reduced acidic deposition by 10

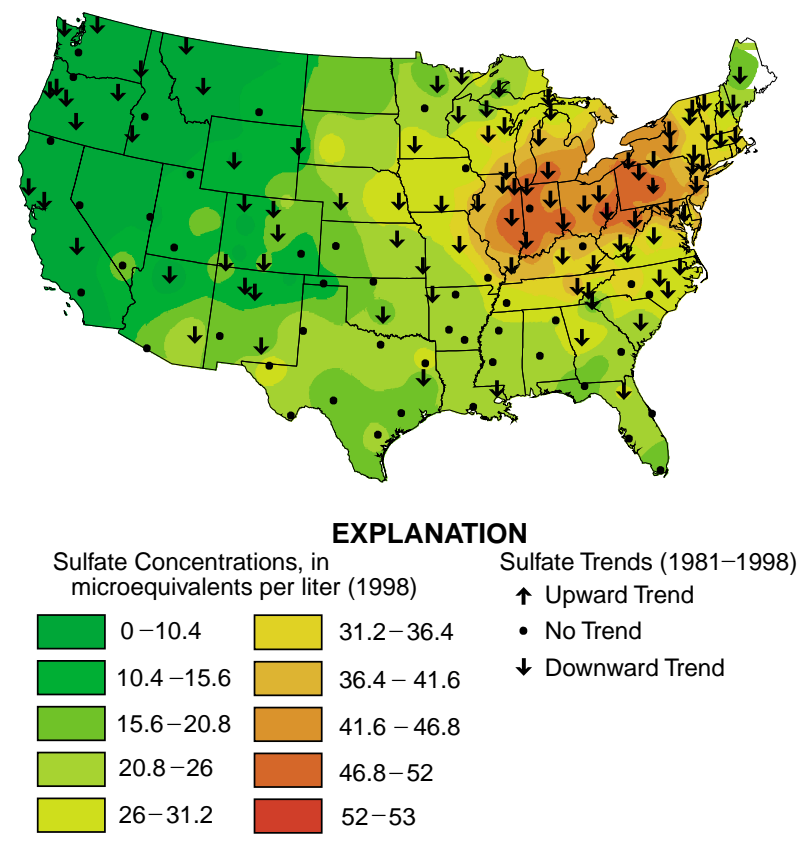

Figure 3. 1981-98 $\mathrm{SO}_{4}{ }^{2-}$ concentrations trends at NADP/NTN sites (arrows) and 1998 estimate annual average $\mathrm{SO}_{4}{ }^{2-}$ concentration (adapted from National Atmospheric Deposition Program, 1999).

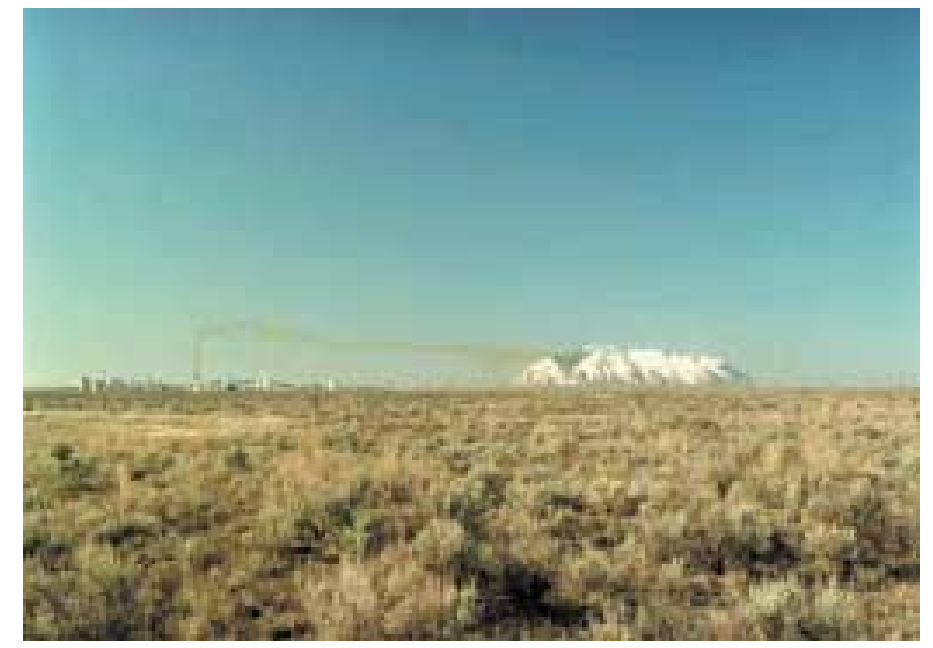

Figure 4. An emission plume from facilities at the Idaho National Engineering and Environmental Laboratory.

to 25 percent in the Eastern United States (National Acid Precipitation Assessment Program, 1998). A more recent analysis (Nilles and Conley, 2000) reinforces these findings (fig. 3).

\section{ESTIMATING NITROGEN DEPOSITION AND ITS SIGNIFICANCE IN AFFECTING AQUATIC AND TERRESTRIAL ECOSYSTEMS}

Nitrogen comprises 78 percent of the atmosphere by weight, primarily in the form of inert $\mathrm{N}_{2}$. A small fraction of atmospheric nitrogen exists in more chemically and biologically active forms, such as nitrogen oxide gases, nitric acid vapor, particulate and dissolved nitrate, gaseous ammonia, dissolved ammonium, ammonium particulates, and organic nitrogen compounds. These forms are active in the nitrogen cycle, which involves the atmosphere, photochemistry, plants, animals, microbes, soils, surface waters, and the oceans. Although reactive nitrogen compounds are produced naturally by several processes, a significant portion of the reactive nitrogen is released to the atmosphere through fossil-fuel combustion, fertilizer application, and intensive animal agriculture. Precipitation readily removes most reactive nitrogen compounds, such as ammonia and nitrogen oxides, from the atmosphere. These compounds are subsequently available as nutrients to aquatic and terrestrial ecosystems.

Estimates of inorganic nitrogen as nitrate and ammonium nitrogen deposited in precipitation in the United States for 1999 are shown in figure 5 .

Because nitrogen is commonly a growth-limiting nutrient in streams, lakes, and coastal waters, increased concentrations can lead to eutrophication, a process involving excess algae production, followed by depletion of oxygen in surface waters as algae die off and are decomposed. Data from the NTN are the primary national source of information from which to estimate nitrogen deposition to ecosystems in the United States. The USGS recently produced estimates of the atmospheric nitrogen inputs to the Mississippi River drainage area (Lawrence and others, 2000) 


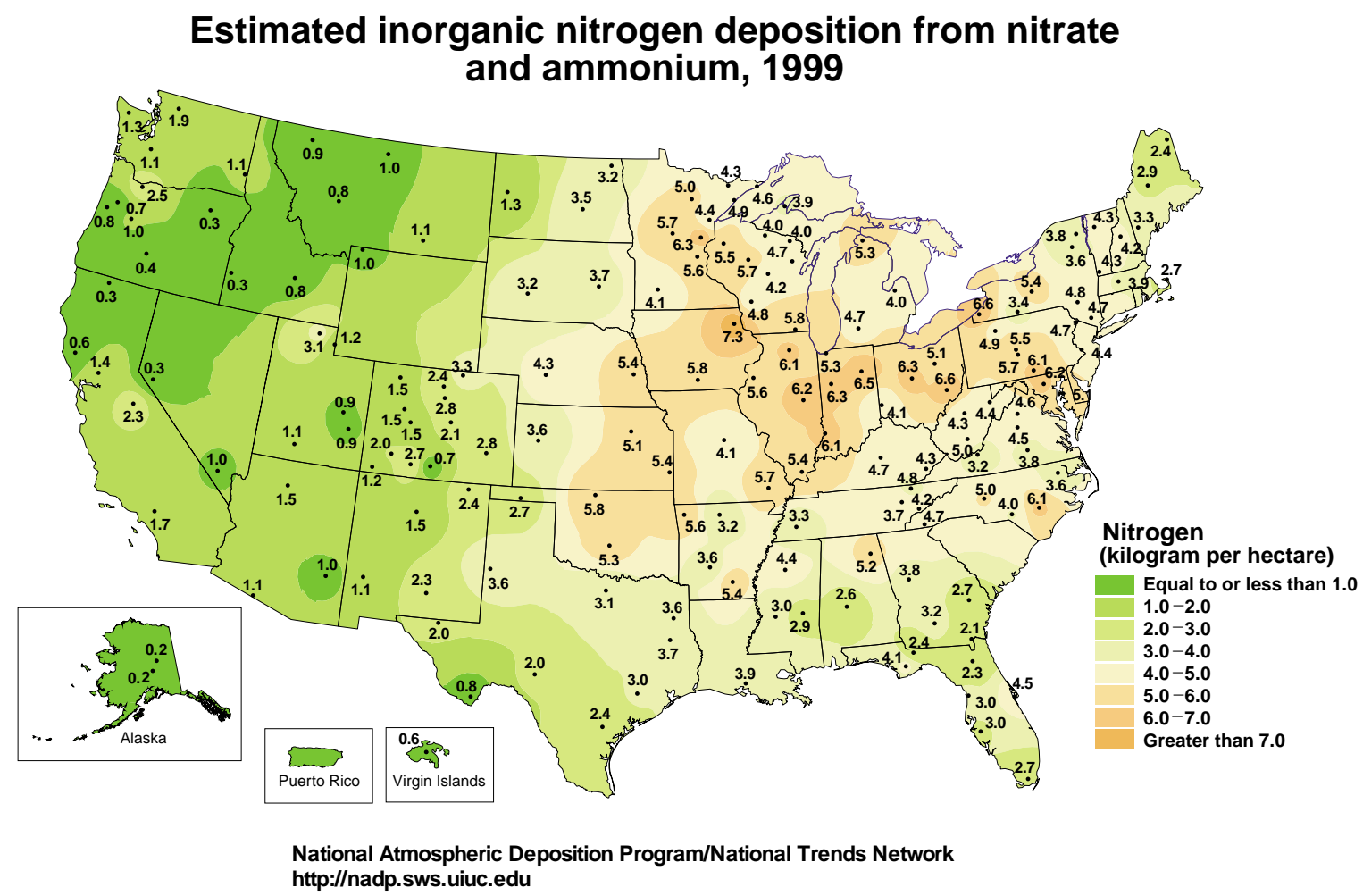

Figure 5. Estimated nitrogen deposition in precipitation from nitrates and ammonium in the United States for 1999 (National Atmospheric Deposition Program , 2000)

as part of a detailed assessment by the National Science and Technology Council's Committee on the Environment and Natural Resources into the causes of the low oxygen (hypoxic) zone, which has adversely affected the productivity of ecosystems and fisheries in the Gulf of Mexico. The NTN data are critical to evaluating the significance of atmospheric inputs of nutrients relative to other sources of nitrogen loading to the gulf and to the many estuarine ecosystems in the United States.

Continued elevated levels of nitrogen deposition have resulted in terrestrial ecosystems, such as some forested watersheds at high elevations in the Northeastern and Rocky Mountain regions of the United States, becoming nitrogen saturated. Nitrogen saturation means that the inputs of nitrogen into the soil exceed the uptake ability by plants and soil microorganisms. Under conditions of nitrogen saturation, excess nitrogen leaches into soil water and subsequently into ground water and surface water. Streams that drain these watersheds have shown increased levels of nitrogen in runoff (National Acid Precipitation Assessment Program, 1998; Williams and others, 1996). This leaching of excess nitrogen from the soils degrades water quality and removes other essential nutrients, such as calcium, needed for plant growth.

\section{DETERMINING THE ROLE OF ATMOSPHERIC DEPOSITION IN SOIL CALCIUM DEPLETION IN THE EASTERN UNITED STATES}

Calcium is an important nutrient for trees and aquatic ecosystems. Accumulating information and data indicates that atmospheric deposition has reduced the availability of acidneutralizing calcium in forest soils in the Eastern United States, with potentially significant adverse consequences for forest productivity and for the ability of surface waters to recover from acidification (Lawrence and others, 1999; Clow and Mast, 1999). Calcium in forest soils is increased by atmospheric deposition, weathering of rocks, and decomposition of calcium-containing organic matter, such as leaves and branches. The loss of calcium in soils is mainly by root uptake and by leaching.

Research in the 1990s, including several studies by the USGS, has shown that (1) calcium in forest soils has decreased at several locations studied in the Northeastern (Lawrence and others, 1997) and Southeastern United States (Lawrence and Huntington, 1999), and (2) acid rain and forest growth (uptake of calcium from the soil by roots) are factors that contribute to calcium depletion (Lawrence and Huntington, 1999). These findings provide regional-scale insight into the processes that contribute to the apparent lack of recovery in the acid-neutralizing capacity of lakes and streams in sensitive ecosystems of the Eastern United States. The lack of recovery at several sites 
studied, despite reductions in acid rain and reductions of sulfate levels in surface-water, appears to be related to depletion of acid-neutralizing calcium and other base cations in forest soils (Lawrence and others, 1999; Clow and Mast, 1999). The occurrence and magnitude of calcium depletion also depends on soil depth, soil chemistry, forest-growth history, and harvesting patterns at specific locations. These studies help to address the policy questions now being debated by the scientific and policy

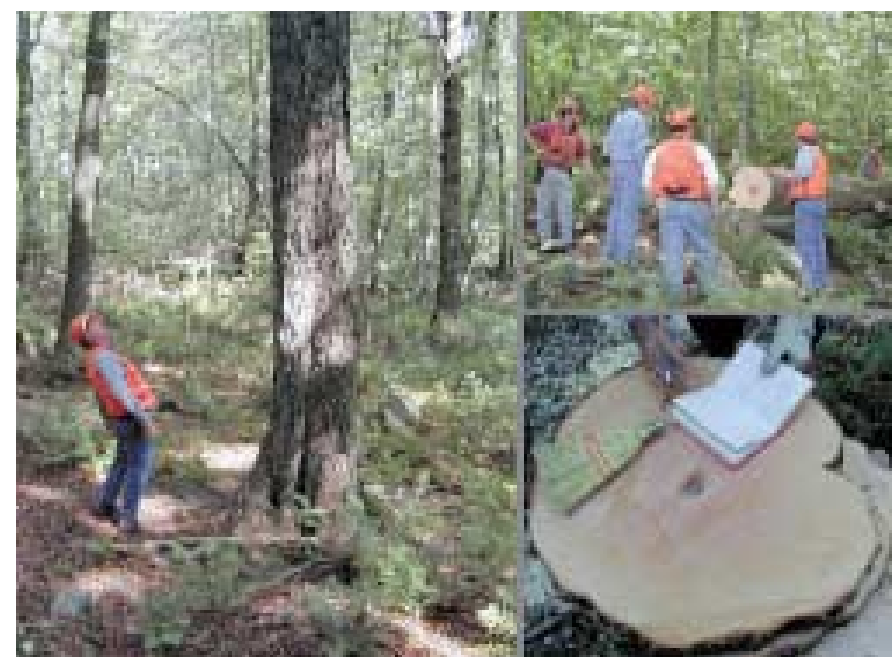

Figure 6. USGS and U.S. Department of Agriculture Forest Service scientists examining the effects of acid rain on soil calcium depletion and sugar maple health near Frost Valley, New York. Photograph courtesy of Ken Dudzik, Forest Service, Northeastern Forest Experiment Station, Durham, New Hampshire. communities as to whether the emission reductions mandated in the Clean Air Act Amendments are sufficient to initiate ecosystem recovery. The data provided by the deposition monitoring program are useful for quantifying the status and trends in acidic deposition and measuring the ongoing decline in atmospheric calcium deposition, while assessments supported by the program provide synthesis of existing USGS studies on calcium depletion.

\section{ESTIMATING DEPOSITION RATES TO SENSITIVE HIGH-ELEVATION ECOSYSTEMS IN THE WESTERN UNITED STATES}

Federal land managers and State regulatory agencies need estimates of atmospheric deposition to prepare resource impact statements and to grant permits for new emission sources that may affect sensitive ecosystems. In addition to deposition estimates from data provided by the NADP sites in the West, the USGS has supported production of enhanced deposition estimates for sensitive high-elevation Western ecosystems by using a total deposition survey. The ecosystems are characterized by dilute surface waters, exposed bedrock or very shallow unbuffered soils, and runoff patterns that are dominated by melting of large snowpacks (National Acid Precipitation Assessment Program, 1990). These areas are not optimally represented by the NTN sites because of logistical problems associated with accessing and operating automated samplers at harsh, snow-dominated, highelevation sites. The annual total-deposition survey roughly follows the Continental Divide northward from New Mexico to the Canadian Border and measures total wintertime deposition by

\section{SUPPORTING THE USE OF NADP DATA BY PROVIDING UNIVERSAL CUSTOMER ACCESS}

A fundamental program objective is to provide scientific investigators worldwide with a long-term, high-quality data base of atmospheric deposition for research support in the areas of air quality, water quality, agricultural effects, forest productivity, materials effects, ecosystem studies, watershed studies, and human health. All NADP data are made available free of charge through the Internet at http://nadp.sws.uiuc.edu. In 1999, investigators downloaded 16,000 datasets in support of research and education. Major data applications include gaging the effectiveness of ongoing emission-control measures, determining nitrogen inputs from atmospheric sources to sensitive ecosystems, and providing regional estimates of mercury deposition in the United States and Canada (Conley and Nilles, 2000). Some recent applications for the data by external customers include:

National Park Service: Determining the effect of rainfall $\mathrm{pH}$ on efforts to reintroduce the leopard frog to Mesa Verde National Park, Colorado.

National Center for Atmospheric Research: Enhancing the accuracy of global climate-change models by accounting for the influence of nitrogen deposition on global carbon-fixation rates.

U.S. Environmental Protection Agency: Determining the relative contribution of atmospheric deposition of nitrogen to the overall nitrogen budget of the Chesapeake Bay watershed.

City of New York: Estimating atmospheric chemical loads to public-supply reservoirs.

National Acid Precipitation Assessment Program: Assessing the effectiveness of industrial and powerplant emission reductions under the Clean Air Act Amendments, Title IV, on reducing acidic atmospheric deposition.

U.S. Department of Defense: Providing precipitation chemistry data for a study examining maintenance practices to reduce galvanic corrosion on F-18 fighter jets.

State of North Carolina: Documenting changes in ammonium deposition in North Carolina relative to growth of confined animal agriculture facilities and estimating the potential impacts of ammonia emissions on air and water quality.

Ford Motor Company: Examining possible effects of precipitation chemistry on automotive paints.

Teachers and students: About 40 percent of all applications for the program's monitoring data are for use in science education, ranging from elementary school to college graduate-level studies. 
analyses of snow cores collected at the time of maximum snowpack accumulation (early spring). Preliminary results from this sampling are provided in figure 7, which indicates substantial variation in ammonium deposition. Accurately determining nitrogen inputs from ammonium and nitrate deposition is of major interest because increasing nitrogen concentrations in stream water have been linked to nitrogen saturation of soils in sensitive watersheds (Williams and others, 1996).

USGS scientists are now comparing data from these surveys with data from NADP/NTN sites and data from a network of snowpack-accumulation sensors located throughout the Rocky Mountains (SNOTEL). Data synthesis and modeling of relationships between elevation and deposition will provide Federal and State land managers with a new, high-resolution picture of atmospheric deposition in the Rocky Mountain region. As Federal and State policies that are aimed at understanding and improving air-quality-related issues in protected public lands in the region evolve, enhanced estimates of deposition to

\section{Ammonium Ion Levels in Snowpack for 1993-97 in the Rocky Mountain Region}

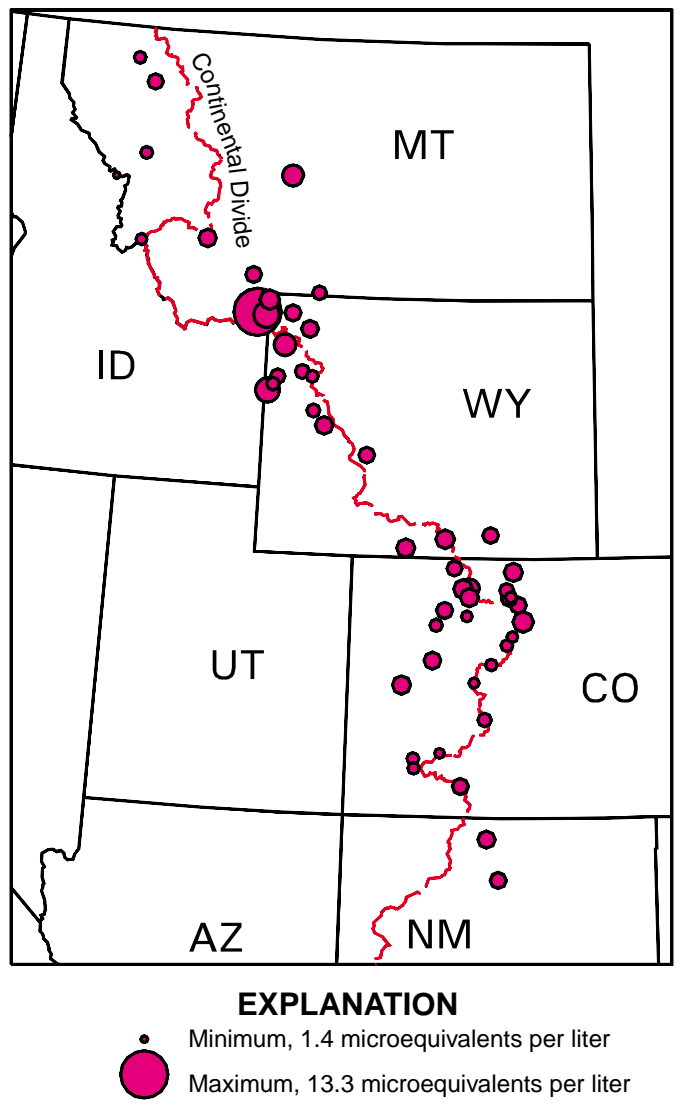

Figure 7. Ammonium ion levels in snowpack for 1993-1997 in the Rocky Mountain region. these sensitive ecosystems are vital to relate atmospheric emissions to observed aquatic and terrestrial effects.

\section{THE FUTURE}

Some emerging issues provide direction for program priorities in data interpretation, research, and infrastructure needs for the next decade and beyond.

Emission trading. The acid rain reduction provisions of the Clean Air Act Amendments incorporate innovative "free market" approaches to accomplishing environmental objectives (Burtraw and Mansur, 1999). These approaches include emission banking and trading, whereby utilities can accumulate, trade, and sell emissions allowances earned by exceeding emission-reduction targets. These provisions are controversial in the Northeastern United States where critics contend that these mechanisms may increase allowable emissions in the Midwest and result in increased deposition of acidic compounds to sensitive ecosystems "downwind" in the East. Although Federal legislation places no regional restrictions on emission allocation trading, States in the East have called for restrictions on trading of emission credits from Eastern utilities to utilities in Midwestern States "upwind" of sensitive ecosystems. Since 1995, emission reductions have significantly exceeded mandates, resulting in a buildup of emission allowances during the first phase of the program that ended in 1999. Citizens and environmental groups have raised concern that depletion of builtup allowances, beginning in 2000 and continuing through 2010 , may increase emissions and subsequent atmospheric deposition in the first decade of this century. The monitoring network the USGS supports will provide the data to determine if, indeed, acidic deposition patterns have changed in 2000 and beyond.

Electric utility deregulation. The process of electric utility deregulation is accelerating at the State and Federal level. There is concern that deregulation of utilities may increase the use of coal and emissions from large coal-fired powerplants, resulting in significant adverse changes in the magnitude and areal extent of chemical substances deposited from the atmosphere. Data from the program will be used to ascertain if this is occurring.

Nitrogen deposition. Ammonium deposition is increasing at some of the NADP monitoring sites and may be coincident with growth in confined animal agriculture facilities in these regions. Although stricter controls of sulfur dioxide emissions have reduced sulfate deposition, emissions of nitrogen oxides and subsequent nitrate deposition have not decreased in the United States (Nilles and Conley, 2000). Increased nitrogen mobilization and distribution from ammonia compounds and nitrates can result in changes in nutrient runoff, precipitation acidity, and watershed nutrient status. Assessments to quantify nitrogen loading to sensitive ecosystems will continue to grow in importance for the program.

Infrastructure renewal. Initial sites in the NADP deposition-monitoring network were established in 1978, and a large portion of the network was in place by 1984. The current sampling equipment has been operating continuously in the field for an average of 17 years, and there has been no substantial 
upgrade or refurbishment of the sampling equipment since installation. A major refurbishment and/or replacement program is needed to prevent the aging equipment from adversely affecting the operational readiness of the program. Testing of off-the-shelf modern recording precipitation gages is well underway, and design of a new prototype deposition sampler began in 2000. The overall objective of this work is to develop and deploy, on a network-wide basis, a modern and more flexible deposition sampling system, one that would not only support all current NADP sampling protocols but also provide the capability to sample precipitation for chemicals of emerging interest (for example, organic compounds).

\section{REFERENCES CITED}

Burtraw, D., and Mansur, E., 1999, Environmental effects of $\mathrm{SO}_{2}$ trading and banking: Environmental Science and Technology, v. 33, no. 20, p. 3489-3494.

Clow, D.W., and Mast, M.A., 1999, Long-term trends in stream water and precipitation chemistry at five headwater basins in the Northeastern United States: Water-Resources Research, v. 35, no. 2, p. 541-554.

Conley, B., and Nilles, M.A., 2000, Uses of National Atmospheric Deposition Program/National Trends Network Data, May 1998 to June 1999; U.S. Geological Survey Open-File Report 00-52, p. $1-6$.

Electric Power Research Institute, 1996, Environmental risk analysis: Environmental update, v. 10, no. 1, p. 1-3.

Gordon, J.D., 1999, External quality-assurance results for the National Atmospheric Deposition Program/National Trends Network, 1995-96: U.S. Geological Survey Water-Resources Investigations Report 99-4072, $62 \mathrm{p}$.

Lawrence, G.B., David, M.B., Bailey, S.W., and Shortle, W.C., 1997, Assessment of calcium status in soils of red spruce forests in the northeastern United States: Biogeochemistry, v. 38, p. 19-39.

Lawrence, G.B., David, M.B., Lovett, G.M., Murdoch, P.S., Burns, D.A., Stoddard, J.L., Baldigo, B.P., Porter, J.H., and Thompson, A.W., 1999, Soil calcium status and the response of stream chemistry to changing acidic deposition levels: Ecological Applications, v. 9, no. 3, p. 1059-1072.

Lawrence, G.B., Goolsby, D.A., Battaglin, W.A. and Stensland, G.J., 2000, Atmospheric nitrogen in the Mississippi River Basin Emissions, deposition and transport: The Science of the Total Environment v. 248 p. 87-99

Lawrence, G.B., and Huntington, T.G., 1999, Soil-calcium depletion linked to acid rain and forest growth in the Eastern United States: U.S. Geological Survey Water-Resources Investigations Report 98-4267, $12 \mathrm{p}$.

Lynch, J.A., 1996, Trends in precipitation chemistry in the United States, 1983-94 — An analysis of the effects of phase I of the Clean Air Act Amendments of 1990, Title IV: U.S. Geological Survey Open-File Report 96-0346, p. 12-13.

National Acid Precipitation Assessment Program, 1990, Acidic deposition - State of science and technology report 12, episodic acidification of surface waters due to acidic deposition: Washington, D.C., p. 100.
National Acid Precipitation Assessment Program, 1998, NAPAP biennial report to Congress - An integrated assessment: Silver Springs, Md., p. 35 .

National Atmospheric Deposition Program, 2000, 1999 Wet deposition: Champaign, Illinois State Water Survey, 16 p.

National Atmospheric Deposition Program, 1999, 1998 Wet deposition: Champaign, Illinois State Water Survey, 16 p.

Nilles, M.A., and Conley, B.E., in press, Changes in the chemistry of precipitation in the United States, 1981-1998: Water, Air and Soil Pollution.

Williams, M.W., Baron, J.S., Caine, N., Sommerfeld, R., and Sanford, R., 1996, Nitrogen saturation in the Rocky Mountains: Environmental Science and Technology, v. 30, no. 2, p. 640-645.

U.S. Environmental Protection Agency, 1998, National air quality and emissions trend report, 1997: Research Triangle Park, North Carolina, EPA 454/R-98-016, p. 112-117.

—By Mark A. Nilles

For more information contact:

Atmospheric Deposition Program Coordinator

U.S. Geological Survey

Box 25046, MS401

Denver, CO 80225

(303) 236-1878

This report and related information can be accessed on the World Wide Web at http://bqs.usgs.gov/acidrain

The use of brand, trade, or firm names in this report is for descriptive purposes only and does not constitute endorsement by the U.S. Government. 